\title{
Reseña del libro de Francisco Rodríguez Cascante: Lisímaco de mí. San José: Fundación Interartes para la cultura y las artes en América Central, 2013. Colección Creación Literaria
}

\author{
Gastón Gaínza1
}

Recepción: 2 de diciembre de 2013 / Aprobación: 27 de junio de 2014

costumbrado a conocer los estudios y comentarios sobre teoría y producción literarias del Dr. Francisco Rodríguez Cascante, ha sido para mí toda una novedad -por cierto, muy satisfactoria- enfrentarme a este producto dramatúrgico de su capacidad artística literaria que, en un delicado proceso dialógico, tensa los límites discursivos entre el drama y el ensayo biográfico.

La condición literaria artística de este libro se pone en evidencia desde su propio título que anticipa, además del fervor por el personaje Lisímaco, la conmovedora certeza de la pasión que fue su vida. Lo confirma el hecho de que esas tres palabras sean, por lo demás, las que ponen fin a la obra, en el instante previo a la caída del telón. Esa expresión del personaje Fanny, en la escena en que verifica horrorizada la muerte de Lisímaco, resume todo el dolor de la pérdida. En ella, el mostrativo "mí", núcleo de la determinación nominal atribuida a "Lisímaco", denota el desgarramiento interior que la aflicción le ha causado, acentuada estilísticamente por la secuencia que la precede²:

"Fanny: (Con rostro de inmenso dolor, se arrodilla a su lado, lo abraza, lo besa, le toma la cabeza con gesto de infinita ternura) ¡Oh Lisi, mi amor, mi Lisímaco, Lisito mío, Lisímaco de mi!!"

Asimismo, reconozco que las escenas de este drama que más me sorprenden, son las del careo literario que los personajes don Ricardo y don Alejandro idean y llevan a la práctica para dilucidar la autoría del poema

\footnotetext{
1 Chileno. Licenciado en Filología por la Universidad de Chile. Profesor retirado de la Universidad de Costa Rica (UCR). Investigador y miembro del Consejo Científico del Centro de Investigación en Identidad y Cultura Latinoamericanas, UCR. Correo electrónico: comedcic@gmail.com

2 Solo en la última expresión de ella, "mí" funciona como sustantivo; los "mi" y el "mío" precedentes, en cambio, son adjetivos.
} 
"Fantasía", entre Rosa Corrales y Lisímaco Chavarría. Este acontecimiento ocurre en el tercer acto y, por su intermedio, el narrador-presentador ${ }^{3}$ del texto despeja la incertidumbre suscitada por el equívoco juego de la condición de autora que Lisímaco, por prejuicios sociales, había endosado a la que, entonces, era su esposa.

Estoy convencido de que mi lectura sobre la prueba de reelaboración discursiva de un supuesto error expresivo del poema (inventado por los árbitros del litigio), para comprobar la autoría real de una obra -y, por lo mismo, la que éticamente le corresponde-, es deudora de un intertexto de mis ya remotos años de estudiante de Filología hispánica. No pude evitar al leer este episodio del drama de Francisco Rodríguez, el recuerdo de la monumental obra de Menéndez Pidal sobre el Cantar de Mío Cid, y su referencia al "juicio de Dios" u ordalía a que recurre el héroe castellano para lavar la afrenta de los Infantes de Carrión.

Pero, superado el valor anecdótico del dialogismo de mi lectura, hay que reconocer la fuerza expresiva que le confiere al texto el formidable recurso pragmático que utilizan los atribulados jueces del pleito, poniendo a prueba la destreza discursiva de los litigantes para comprobar las virtudes expresivas de su elocuencia. La abrumadora superioridad de estas en el texto elaborado por Lisímaco -sumada a los testimonios que él había presentado- permite dilucidar de manera irrefutable la duda planteada.

La comparación de este episodio del drama con la historia de las circunstancias reales que, en su momento, permitieron esclarecer la autoría de las obras de Lisímaco Chavarría publicadas bajo el nombre de Rosa Corrales de Chavarría, es una labor ociosa, habida cuenta del carácter artístico del texto Lisímaco de mí, cuyos personajes, acontecimientos y cronotopo responden a un proceso de modelización secundaria del género discursivo literario dramatúrgico.

Con todo, este juego entre ficción y realidad es el elemento constitutivo fundamental de Lisímaco de mí. Es posible que Francisco Rodríguez lo haya producido tras considerar que la opción de reducir la materia narrativa de la vida de Lisímaco al ensayo biográfico, provocaría una sensible pérdida del sentido trágico que, en cambio, el drama permite realzar. Y si fuese así, hay que agradecerle tan atinada preferencia, porque, en mi opinión, la dramaturgia es el medio más eficaz para denotar una existencia tan patética como la del poeta Lisímaco Chavarría Palma. El efecto de la ficción reproduce con mayor dramatismo los claroscuros de su vida.

En la otra dimensión del texto que reseño, que antes llamé "realidad", se despliega la historia de la existencia del poeta. Es decir, las relaciones sociales de la producción y reproducción material de su vida. Sus padres, sus hermanos, las mujeres con quienes formó pareja, sus amistades y, en fin, las

3 Utilizo este término para diferenciarlo de "narrador" a secas, válido para el género literario narrativo remotospectivo. 
personas que tuvieron significación relevante en el desarrollo y progreso de su capacidad artística.

Todos esos seres y sucesos constituyen un material de referencia, de una u otra forma, evocado -modelizado, en términos de Lotman-, con diestras caracterizaciones de personajes y certeras elaboraciones de acontecimientos, en la estructura del drama. La urdimbre de este tejido artístico supone, sin embargo, al unísono, tanto un proceso de selección económica de la información biográfica, como la introducción de elementos distintivos del carácter de ficción del texto.

Cuando asistí a la presentación de la edición de este drama en la Sede de Occidente de la Universidad de Costa Rica me enteré, además, de que al día siguiente se efectuaría la presentación de las Obras completas de Lisímaco Chavarría, de cuya monumental edición es responsable, justamente, Francisco Rodríguez, autor, asimismo, del Estudio introductorio de la obra (Chavarría, 2013).

Así fue como supe que, tras la acuciosa investigación de los datos biográficos del poeta ramonense, Francisco Rodríguez había logrado demostrar que el nacimiento de Lisímaco Chavarría fue en 1873, y no en 1878, como los historiadores de la literatura costarricense habían aceptado hasta ese momento y sin mayor análisis.

Demasiado tarde me enteré de este singular hallazgo de las investigaciones del autor de Lisímaco de mí, porque minutos después de haberlo sabido tuve que leer mi texto de presentación de esa obra, en el que, por supuesto, yo repetía erróneamente que el poeta había nacido en 1878 e interpretaba que la datación propuesta por el autor era un recurso estilístico para dar al personaje una ventaja de madurez y experiencia vital. (Reconozco que, no sin atribulado avergonzamiento, dejé constancia de mi error ante el auditorio).

Dos factores contribuyeron a que me engolosinase con el equívoco del año de nacimiento. Uno fue producto de un sugestivo, aunque erróneo, dialogismo con Mamita Yunai, de Carlos Luis Fallas ${ }^{4}$. El otro era suponer, también erróneamente, que Francisco Rodríguez había decidido, como autor del drama, hacer coincidir el año de la muerte del personaje Lísimaco con el de su cuadragésimo cumpleaños, para intensificar el trágico desenlace de su vida.

Superados estos errores gracias a la labor investigadora de Francisco Rodríguez, el drama muestra, en términos dialógicos, que el personaje remite de manera real a la biografía del poeta Chavarría, cuya madurez y experiencia vital están acordes con las virtudes de su producción lírica, tan adecuadamente acentuada en el texto dramatúrgico.

$4 \quad$ El narrador de esta novela es el personaje José Francisco Sibaja y los acontecimientos en que participa coinciden, en gran medida, con los vividos por su autor, Carlos Luis Fallas quien, para evitar la lectura autobiográfica del relato, asigna al personaje una edad mayor que la de él. 
Asimismo, y también por la vía del dialogismo, el dramatismo de la muerte del personaje en el drama se multiplica, habida cuenta de que su muerte, a los 40 años, se produjo en una edad que, entre muchas interpretaciones, el imaginario colectivo ha considerado, a la vez, fin y cumplimiento de un ciclo de preparación y aprendizaje, y comienzo de otro, en que ese ejercicio y ese saber deben ponerse a prueba (Chevalier y Gheerbrant, 1982).

Con esta obra, Francisco Rodríguez inaugura en Costa Rica una dramaturgia en la que la conjunción entre la ficción y la realidad, asumida sin retórica, realza los hechos históricos con la economía de su transformación semiótica en arte. Realza su empresa, la habilidosa articulación selectiva de productos del discurso lírico del protagonista que, para consolidar la perspectiva biográfi$\mathrm{ca}$, remiten a la labor creativa del poeta ramonense evocado en el texto.

Un lector atento percibirá la finura de los trazos caracterizadores de los personajes que interactúan con Lisímaco, repletos de información veraz sobre autores de la literatura costarricense que les sirven de referentes. Francisco Rodríguez ha aprehendido en buena fuente esa labor. Lo comprueba uno de sus estudios sobre la producción literaria centroamericana en que, precisamente, el dialogismo de la ambigüedad del texto narrativo pone en tensión los límites entre géneros discursivos distintos, aunque próximos en su configuración semiótica5.

Espero que Lisímaco de mí sea la primera cuenta de un precioso collar de nuevas aventuras literarias de Francisco Rodríguez, mi amigo.

Campus Rodrigo Facio, octubre de 2013.

\section{Referencias}

Chavarría, Lisímaco. (2013). Estudio Introductorio. En Rodríguez Cascante, Francisco. (Ed.). Obras completas. San José: Editorial de la Universidad de Costa Rica. 2 Vols.

Chevalier, Jean y Gheerbrant, Alain. (1982). Dictionnaire des symboles. Paris: R. Laffont et Jupiter. Edición revisada y corregida.

5 Me refiero a su libro Autobiografía y dialogismo: el género literario y 'El río, novelas de caballería'. San José: Editorial de la Universidad de Costa Rica, 2004. Con prólogo de Sergio Ramírez. Colección Identidad Cultural. 